\title{
In situ polymerization of 4-(methacryloylamino) phenyl-2-methylacrylate on the surface of silica gel
}

Elina Yanovska ${ }^{\mathrm{a}}$, Lyudmyla Vretik ${ }^{\mathrm{a}}$, Dariusz Sternik ${ }^{\mathrm{b}}$, Olga Kychkiruk ${ }^{\mathrm{c}}$, Olena Nikolaeva ${ }^{\mathrm{a}}$, Iana Buriachenko $^{\mathrm{a}}$

${ }^{a}$ Chemistry Department, Taras Shevchenko National University of Kyiv, 12 L. Tolstogo St., 01033 Kyiv, Ukraine

${ }^{b}$ Maria Curie-Skłodowska University, 2 Maria Curie-Skłodowska Sq., 20-031 Lublin, Poland

${ }^{c}$ Department of Sciences, Ivan Franko Zhytomyr State University, 40 Velyka Berdychivska St., 10008 Zhytomyr, Ukraine

e-mail : elina_yanovska@ukr.net

Keywords: phenylmethylacrylate, modified silica, in situ immobilization, metal complexes, adsorption properties.

Immobilization of 4-(methacryloylamino)phenyl-2-methylacrylate homopolymer on the silica gel surface has been carried out in situ. The structure and quantitative characteristics of immobilized polymer have been examined by IR spectroscopy, thermogravimetric analysis and mass spectrometry. Adsorption activity towards microquantities of $\mathrm{Pb}(\mathrm{II}), \mathrm{Cu}$ (II), $\mathrm{Mn}(\mathrm{II}), \mathrm{Co}(\mathrm{II})$, $\mathrm{Ni}(\mathrm{II})$ and $\mathrm{Fe}(\mathrm{III})$ ions in the range of $\mathrm{pH}$ 6-8,5 has been observed. Quantitative adsorption of traces of $\mathrm{Pb}(\mathrm{II})$ in neutral and slightly alkaline media is reported.

\section{Introduction}

In the last two decades significant progress has been achieved in the study of complexing processes on solid surfaces as well as in general methods of targeting synthesis of major groups of complexing adsorbents, including chemically modified complexing silica $[1,2]$. There have been many examples of solid carriers with proven efficiency in catalytic processes, development of hybrid and combined methods in analytical chemistry with enhanced limits and accuracy of chemical elements determination and reducing analysis time.

In particular, research efforts have been aimed at finding targeted one-step synthetic methods for creation of adsorbent with monofunctional complexing coating on solid surface.

To increase the sorption capacity of adsorbents, adsorption or chemical attachment to inorganic surfaces of N,O-containing polymers with complexing and ion-exchange properties (polyionens, polyhexamethylene- 
guanidine and its derivatives, polyaniline, polyacrylic acid) is thus increasingly used [3$6]$.

To synthesize these materials, in situ formation of immobilized polymer layer in the presence of inorganic carrier particles is to be used as a promising way of creating nanocomposites with new valuable properties. To form a polymeric layer we use well studied $[7$ monomer $4-$ (methacryloylamino) phenyl-2-methylacrylate bearing two double bonds with different reactivity in radical polymerization process.

At the initial stage of polymerization non-cross-linked polymer product is formed due to more active methacrylate double bond. With conversion of more than 30 mass.\% formation of insoluble cross-linked product is observed due to simultaneous polymerization of methacrylate and metacrylamide groups [8]. In addition, compounds with similar structure are capable to undergo Fries photo-rearrangement [9-15], resulting in the formation of complexing oxo- and aminoketone functions [16]. The presented paper is devoted to in situ immobilization of 4-(methacryloylamino) phenyl-2-methylacrylate homopolymer on the silica gel surface and investigation of immobilized surface obtained as well as its adsorption properties towards $\mathrm{Cu}$ (II), $\mathrm{Pb}$ (II), $\mathrm{Mn}$ (II), $\mathrm{Fe}$ (III), Ni (II) and Co (II) ions.

\section{Experimental part}

Homopolymerization

of $4-$ (methacryloylamino)phenyl-2-methylacrylate in the presence of silica gel (fraction of $0.1-0.2$ $\mathrm{mm}$ diameter particles, specific surface of $428.61 \mathrm{~m}^{2} / \mathrm{g}$, Merck) is carried out in an inert atmosphere, created by blowing argon for 25 minutes. $0.042 \mathrm{~mol}$ 4-(metacryloylamino) phenyl-2-methylacrylate and $0.1 \mathrm{~g}$ of azobisisobutyronitrile (AIBN) is dissolved in 50 $\mathrm{mL}$ of $\mathrm{N}, \mathrm{N}$-dimethylformamide, poured into the reactor with $20 \mathrm{~g}$ of silica gel added while stirring. After the interruption of argon blowing, the reaction mixture is heated to $80{ }^{\circ} \mathrm{C}$. After 25 minutes the reaction mixture in form of gel is removed from the reactor, ground in a mortar and washed five times with ethanol. After drying the resulting silica gel coated with polymer and divided into 6 portions, is exposed for $20 \mathrm{~min}$ to UV light DRSH-600 mercury lamp (light intensity $100 \mathrm{~mW} / \mathrm{cm}^{2}$ ) in a $14 \mathrm{~cm}$ diameter porcelain bowl. As a result of UV light exposure the top layer of the composite material changes its color from white to beige due to the formation ortho-amino and orthooxiketone structures $[11,13,16]$

IR spectra of the composite and parent silica gel have been recorded with Thermo Nicolet Nexus FT-IR, USA Fourier transform infrared spectrophotometer.

The quantity of copolymer on the silica gel surface is evaluated by thermogravimetric analysis data obtained with TG/DTA analyzer «Shimadzu DTG-60 H» (Japan) in temperature range $15-1000{ }^{\circ} \mathrm{C}$. The heating rate of samples is $10^{\circ} \mathrm{C} / \mathrm{min}$. 
For the specific surface area and average pore diameter of the composite determination, the BET instrument ASAP 2420 V1.01 (Micromeritics Instrument Co., USA) at the boiling point of liquid nitrogen is used. Before measuring, the samples are degassed at $60{ }^{\circ} \mathrm{C}$. The isotherm plots are used to calculate the specific surface area and the average pore diameter of poly(4-(metacryloylamino) phenyl2-methylacrylate)-silica composite.

Thermal analysis was carried out on a STA 449 Jupiter F1, Netzsch (Germany) under the following operational conditions: heating rate of $10^{\circ} \mathrm{C} \mathrm{min}^{-1}$, dynamic atmosphere of synthetic air $\left(50 \mathrm{~mL} \mathrm{~min}^{-1}\right)$, temperature range of $30-950{ }^{\circ} \mathrm{C}$, sample mass $\sim 18 \mathrm{mg}$, sensor thermocouple type S TG-DSC. As a reference empty $\mathrm{Al}_{2} \mathrm{O}_{3}$ crucible was used. The gaseous products emitted during decomposition of material were analyzed by QMS 403C Aeölos (Germany) coupling on-line to STA instrument. The QMS data were gathered in the range from 10 to $160 \mathrm{amu}$.

Adsorption characteristics of synthesized composite material with respect to $\mathrm{Cu}(\mathrm{I}), \mathrm{Pb}$ (II), Mn (II), Fe (III), Ni (II) Co (II) ions are investigated in static mode. For such investigations, the sample of $0.1 \mathrm{~g}$ of synthesized composite is in contact with $25-100$ $\mathrm{ml}$ of solutions of nitrates of the above mentioned metals while constantly stirred with a mechanical vibrator at room temperature.

Determination of the equilibrium concentration of the metals is carried out by atomic absorption using a flaming atomic absorption spectrophotometer "Saturn" (Ukraine) in a "air - propane - butane" flame mixture.

The degree of adsorption (R) is calculated using the formula:

$$
R=\left(m_{\mathrm{ads}} / m_{\mathrm{o}}\right) \cdot 100 \%=\left(m_{\mathrm{o}}-m\right) / m_{\mathrm{o}} \cdot 100 \%
$$

(1),

where $m_{\mathrm{o}}$ - mass of metal in the output solution, $m_{\text {ads }}$ - mass of adsorbed metal, m - mass of metal in the equilibrium solution after adsorption, which is calculated as $m=[\mathrm{M}] \cdot V$, where $[\mathrm{M}]$ - equilibrium concentration of metal and $V$-volume of equilibrium solution.

Nitrate solutions of $\mathrm{Cu}$ (II), $\mathrm{Pb}$ (II), $\mathrm{Mn}$ (II), Fe (III), Ni (II) Co (II) are prepared with the sets of "standard sample solutions" of these salts on $1 \mathrm{M} \mathrm{HNO}_{3}$ background (produced by A.V. Bogatsky FHI, Odesa) with concentrations of 1 and $10 \mathrm{mg} / \mathrm{mL}$ Buffer solutions with proper $\mathrm{pH}$ are used (ISO 8,135: 2009, manufacturer JSC "Kyiv Plant RIAP").

Conditions connected with the optimum $\mathrm{pH}$ value of the medium, interaction time in static mode, and adsorption capacity were studied.

\section{Results and discussion}

The scheme of in situ immobilization of 4-(methacryloylamino) phenyl-2-methylacrylate on the silica gel surface and formation of new ortho-amino and ortho-oxiketone functional groups is shown in Scheme 1. 


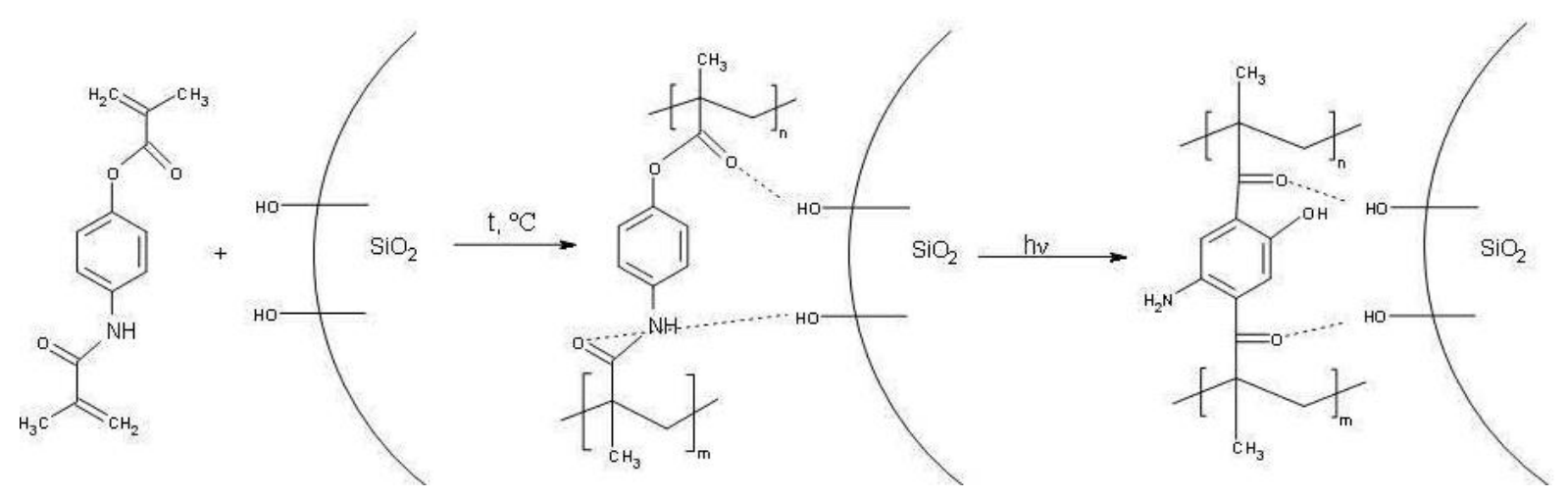

Scheme 1. Chemical reactions of in situ immobilization of 4-(methacryloylamino) phenyl-2-methylacrylate on the silica gel surface and formation of ortho-amino and ortho-oxiketone functional groups [16].

Comparative analysis of IR spectra of In the spectrum of the composite in the composite and parent silica gel show (Figure 1) range of 1380 to $1630 \mathrm{~cm}^{-1}$ absorption bands are that in the spectrum of immobilized polymer absorption bands at $3460 \mathrm{~cm}^{-1}$ can be identified also present, which can be attributed to the as a result of overlapping of stretching vibration of polymer $v(\mathrm{~N}-\mathrm{H})$ - bonds and $v(\mathrm{OH})$ - silica stretching vibration of the aromatic system. Bands in the range of $1200 \mathrm{~cm}^{-1}$, associated with gel bonds. $v(\mathrm{C}-\mathrm{O})$ - vibration and about $800 \mathrm{~cm}^{-1}$ attributed to deformation $\mathrm{CH}$-vibrations of polymer chain [17] are observed.

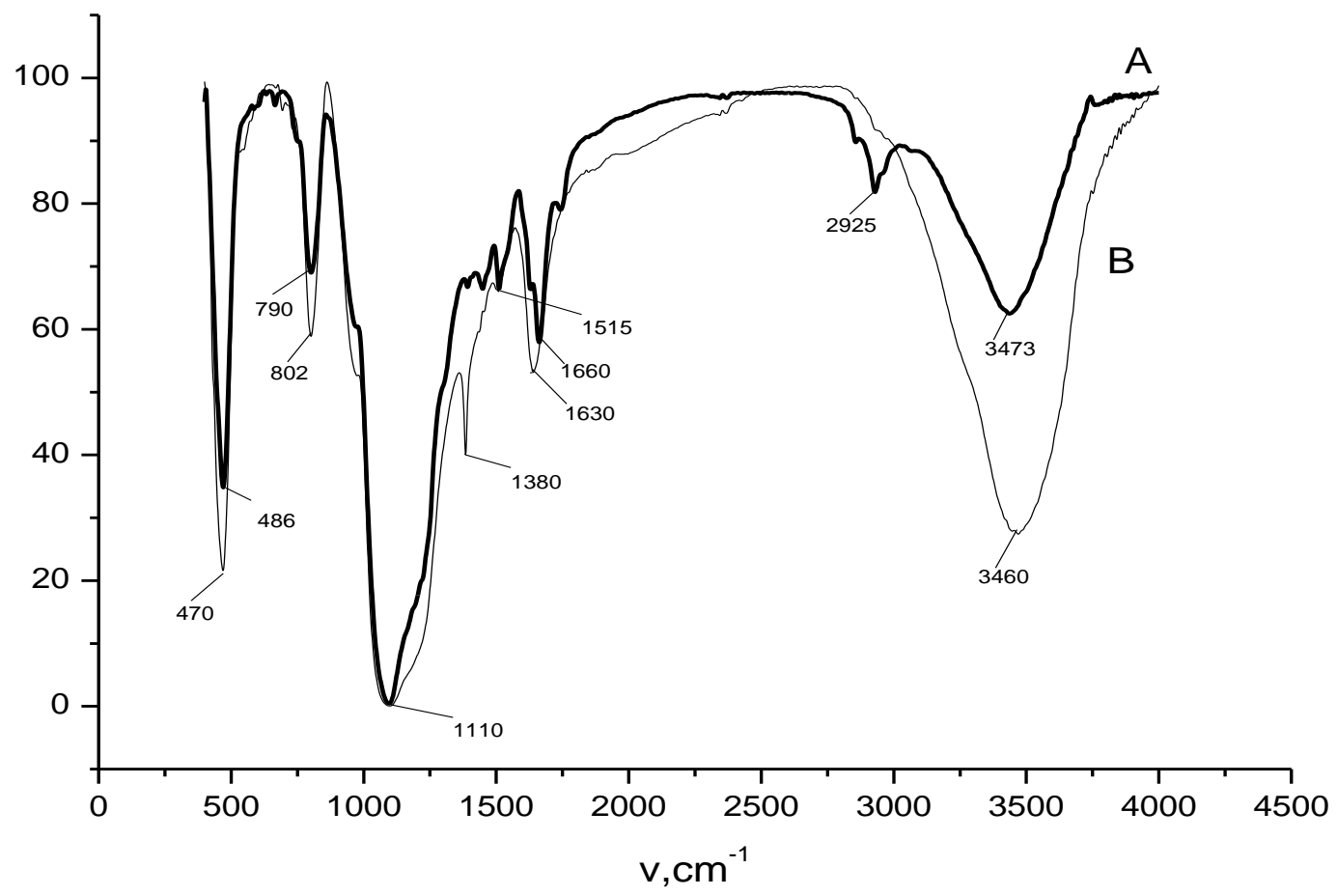

Figure 1. The IR-spectra of initial silica gel (A) and synthesized composite after UV light exposure (B). 
Comparing the results of thermogravimetric analysis for initial silica gel and obtainned composite it is confirmed that hybrid material is formed in result of successful introduction of polymer. As a result of thermogravimetric analysis (Figure 2) it has been found that the composition of synthesized composite includes 27 wt. \% of poly(4(methacryloylamino) phenyl-2-methacrylate).

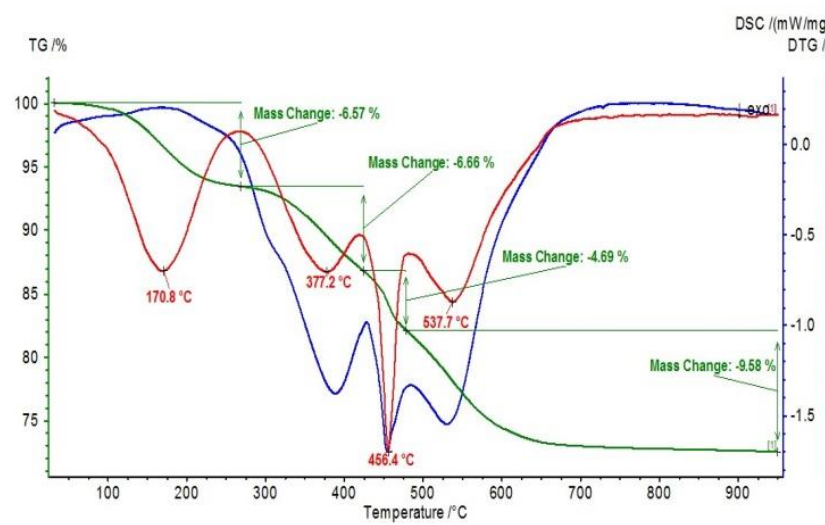

Figure 2. Thermogram of synthesized composite : green line - TG curve, red line - DTG curve, blue line- DSC curve

Mass spectral studies (Figure 3) show that mainly thermal degradation of the polymer is observed at temperatures exceeding $400{ }^{\circ} \mathrm{C}$. The major products with the relative weight of 18 and $44 \mathrm{Da}$ are water and $\mathrm{CO}_{2}$.

As seen in Figure 4, the forms of isotherms of nitrogen adsorption-desorption of the initial silica gel and composite obtained are similar. The shape of the isotherm corresponds to type IV isotherms of the IUPAC classification.

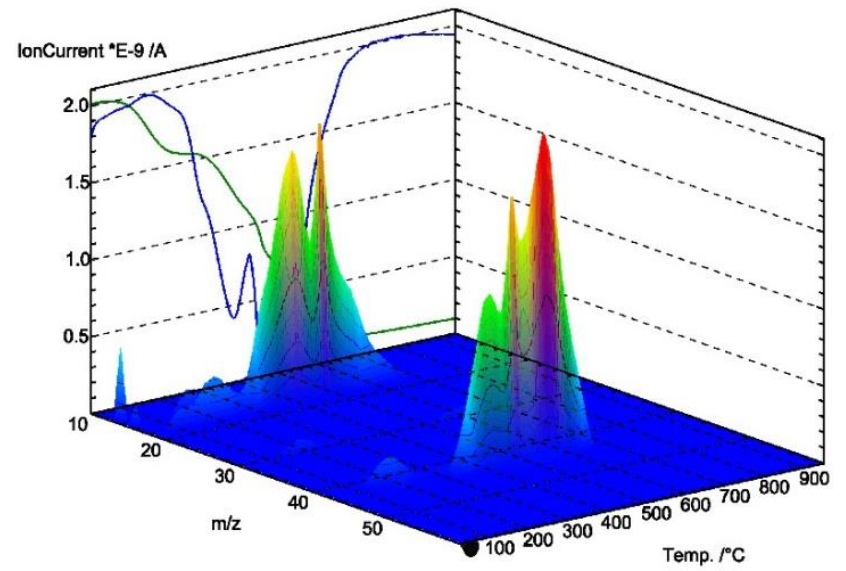

Figure 3 TG-MS-3D of composite.

The obtained data indicate that immobilized polymer has virtually no effect on the structure of the surface layer of silica gel. The value of the specific surface area of silica gel after polymer immobilization calculated using the BET method is $363.24 \mathrm{~m}^{2} / \mathrm{g}$. Thus, the surface area decreases slightly after immobilization, which is a logical result of the formation of fine-pore polymer on the surface.

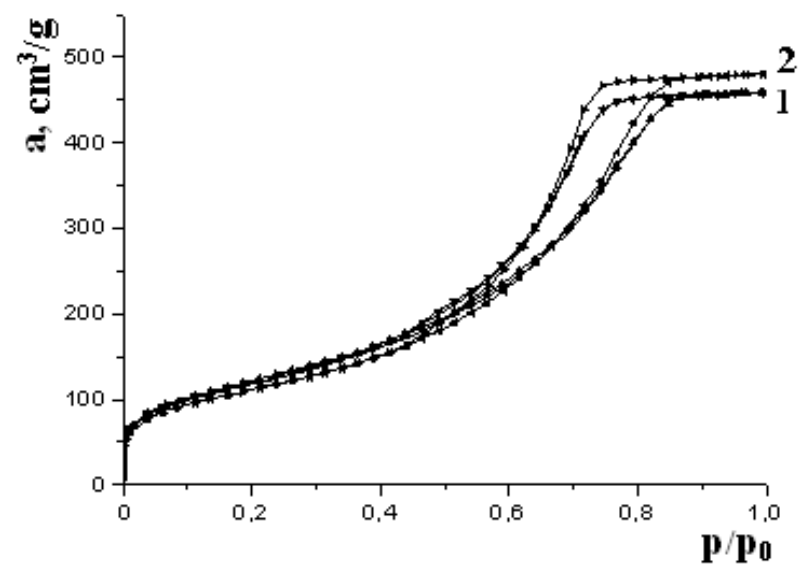

Figure 4. Adsorption-desorption isotherms of nitrogen of parent silica gel (1) and composite (2).

For a more detailed study of the changes in the structure of the silica gel surface after polymer immobilization, a diagram of pore size 
distribution was built, using the BET method. From this diagram it follows that modification virtually has no effect on the pore size of a predominantly macroporous nature of silica. Such pore distribution is usually characteristic of "islet" location on the surface of silica polymer matrix, as confirmed by the scanning electron microscopy SEM data (Figure 5).

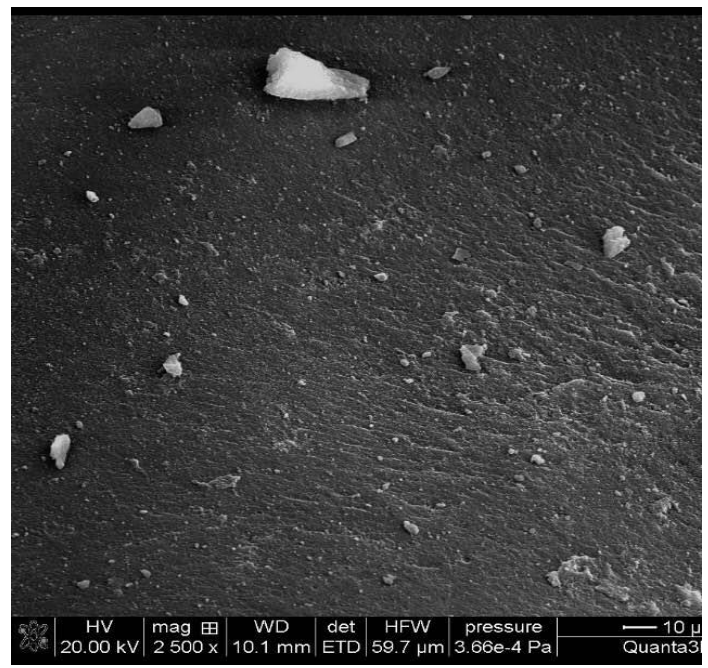

Figure 5. The SEM-microphotographs of silica surface with in situ immobilized poly(4-

(methacryloylamino)phenyl-2-methylacrylate).

It can be seen from the SEM images that polymer was immobilized on the silica gel surface non uniformly, with "islet" location of globules and their aggregates [9].

An adsorption capacity data of synthesized composite towards $\mathrm{Cu}$ (II), $\mathrm{Pb}$ (II), $\mathrm{Mn}$ (II), Fe (III), Ni (II) and Co (II) ions in different $\mathrm{pH}$ media are given in Table 1. It has been found that synthesized composite reveals adsorption activity to detect trace quantities of all the studied metals in $\mathrm{pH}$ range 6-8.5 (assuming there is no initial salt hydrolysis).
Table 1. Dependence of the adsorption degree of metal ions on silica with immobilized poly(4(methacryloylamino) phenyl-2-methacrylate)

(Experimental conditions: sorbent mass - $0.1 \mathrm{~g}$, volume of solutions $-25 \mathrm{~mL}, \mathrm{~m}^{0}{ }_{\mathrm{Me}}-100 \mu \mathrm{g}$ )

\begin{tabular}{|c|c|c|c|c|c|c|}
\hline \multirow{2}{*}{$\mathrm{pH}$} & \multicolumn{6}{|c|}{ Sorption degree, \% } \\
\cline { 2 - 7 } & $\mathrm{Cu}(\mathrm{II})$ & $\mathrm{Co}(\mathrm{II})$ & $\mathrm{Ni}(\mathrm{II})$ & $\mathrm{Mn}(\mathrm{II})$ & $\mathrm{Pb}(\mathrm{II})$ & $\mathrm{Fe}(\mathrm{III})$ \\
\hline 1 & 0.00 & 1.57 & 6.95 & 0.00 & 0.00 & 0.00 \\
\hline 4.01 & 0.00 & 0.53 & 2.00 & 0.00 & 13.21 & 1.84 \\
\hline 6.86 & 30.43 & 6.98 & 5.74 & 99.56 & 96.55 & 13.79 \\
\hline $\begin{array}{c}\text { Dist. } \\
\text { water }\end{array}$ & 96.35 & 4.76 & 55.64 & 81.27 & 99.99 & 98.64 \\
\hline 8.40 & 95.15 & 25.54 & 79.44 & 89.6 & 99.99 & $-*$ \\
\hline 9.60 & 84.68 & 77.78 & $-*$ & $-*$ & 31.62 & $-*$ \\
\hline
\end{tabular}

-*- values missing in the table mean precipitation by hydrolysis of salts after adding the buffer solution prior to contact with the adsorbent

However, as can be seen from Table 1, quantitative adsorption is recorded only for $\mathrm{Pb}$ (II) ions in neutral and slightly alkaline media. When salt solutions of the studied metals contact the surface of the synthesized composite in an acidic medium $(0.1 \mathrm{M} \mathrm{HCl})$ a partial flushing of immobilized polymer into the solution is observed, indicating the inability of application of the composite as adsorbent in an acidic aqueous medium.

Dependence of the adsorption degree of selected transition metal ions from the time of contact in static mode show that all the investigated metal ions are mostly adsorbed during the first minutes of contact, thus indirectly confirming the complexing mechanism of adsorption. 
Adsorption isotherms of all the studied metals have the same shape and according to the Hills and coworkers classification belongs to L2-type isotherms, indicating a uniform distribution of ions adsorbed on the surface of the composite [18].

Calculations of the adsorption capacity of synthesized composite towards the investigated ions are made on the basis of adsorption isotherms, allowing us to suggest (Tabl. 2), that the adsorption capacity of synthesized composite is several times higher then original silica gel adsorption capacity for all studied ions.

Table 2. Sorption capacity of silica with immobilized poly(4- (methacryloylamino) phenyl-2methacrylate) towards ions $\mathrm{Cu}$ (II), $\mathrm{Pb}$ (II) Fe (III) and $\mathrm{Ni}$ (II) in a neutral medium

\begin{tabular}{|c|c|c|c|c|}
\hline \multirow{2}{*}{$\begin{array}{c}\text { Metal } \\
\text { ion }\end{array}$} & \multicolumn{4}{|c|}{ Sorption capacity } \\
\cline { 2 - 5 } & \multicolumn{2}{|c|}{ Parent silica gel } & \multicolumn{2}{c|}{ Composite } \\
\cline { 2 - 5 } & $\mathrm{mmol} / \mathrm{g}$ & $\mathrm{mg} / \mathrm{g}$ & $\mathrm{mmol} / \mathrm{g}$ & $\mathrm{mg} / \mathrm{g}$ \\
\hline $\mathrm{Mn}(\mathrm{II})$ & 0.010 & 0.54 & 0.025 & 1.35 \\
\hline $\mathrm{Cu}(\mathrm{II})$ & 0.006 & 0.38 & 0.021 & 1.34 \\
\hline $\mathrm{Pb}(\mathrm{II})$ & 0.002 & 0.41 & 0.010 & 2.07 \\
\hline $\mathrm{Fe}(\mathrm{III})$ & 0.007 & 0.39 & 0.010 & 0.56 \\
\hline $\mathrm{Ni}(\mathrm{II})$ & 0.001 & 0.06 & 0.011 & 0.65 \\
\hline $\mathrm{Co}(\mathrm{II})$ & 0.002 & 0.12 & 0.014 & 0.81 \\
\hline
\end{tabular}

The adsorption capacity of the obtained composite is not high enough due to the next reason. In the aqueous solutions metal ions exists as aqua complexes and their relatively large size may cause steric hindrances during the adsorption on the complexing centers (e.g. amino-groups) of the immobilized polymer. In the case of globular structure of the polymer accessible are only those centers that are located outside the globule.

The highest increase has been recorded for $\mathrm{Ni}$ (II) and Co (II) ions, the least for Fe (III) ions. These results can be explained by high stability of $\mathrm{Ni}$ (II) and $\mathrm{Co}(\mathrm{II})$ amine complexes [19]. Thus, the results of the research conducted on the adsorption capacity of the synthesized composite material on selected transition metal ions indicate that the cause is complexing of metal ions with aminogroups of the immobilized polymer.

\section{Conclusions}

A new organic composite material has been synthesized by in situ immobilization of 4(methacryloylamino)phenyl-2-methylacrylate homopolymer on the silica gel surface. The fact of heterophase polymerization has been confirmed by IR spectroscopy and mass spectrometry. As a result of thermogravimetric analysis it has been found that the composition of synthesized composite includes 27 wt. \% of polymer. A comparison of adsorptiondesorption isotherms of nitrogen of parent silica and composite shows that immobilized polymer has virtually no effect on the structure of the surface layer of silica gel. Adsorption activity towards microquantitatives of $\mathrm{Pb}(\mathrm{II}), \mathrm{Cu}(\mathrm{II})$, $\mathrm{Mn}(\mathrm{II}), \mathrm{Co}(\mathrm{II}), \mathrm{Ni}(\mathrm{II})$ and $\mathrm{Fe}(\mathrm{III})$ ions in the range of $\mathrm{pH}$ 6.0-8.5, caused by processes of complex formation with aminogroups of immobilized polymer has been revealed. 


\section{References}

[1]. Zaitsev VN. Complexing silica: synthesis, structure of the graft layer and surface chemistry. Kharkov Ukraine: Folio; 1997.

[2]. Lisichkin GV, Fadeev AY., Serdan AA et al, Chemistry grafted surface compounds, Moscow, Russia: FIZMATLIT; 2003.

[3]. Tertykh V, Polishchuk L, Yanishpolskii V, Yanovska

E, Dadashev A, Karmanov V, Kichkiruk O. Recent Advances in Adsorption Processes for Environmental Protection and Security, NATO Science for Peace and Security Series, Dordrecht, Germany: Springer; 2008, p. 119.

[4]. Yanovska ES., Dadashev AD, Tertykh VA. Inorganic anion-exchanger based on silica with grafted polyhexamethyleneguanidine hydrochloride. Func. Mat. 2009; 16(1): 105-9.

[5]. Dadashev AD, Tertykh VA, Yanovska ES, Yanova KV. Ion-Exchange Properties of Modified Silica with Bound Amides of Polyhexamethyleneguanidine and Maleic or $\boldsymbol{o}$-Phthalic Acids Chem. Phys. and Tech. of Surf. 2012; 3(4): 419-28.

[6]. Yanovska ES, Ryabchenko KV, Tertykh VA, Kichkiruk OYu. Chem. Phys. and Tech.of Surf., 2012; 3(4): 439-45.

[7]. Pascal LP, Ph.D. Thesis, Kyiv,Ukraine, 1984 (in Ukrainian).

[8]. Nikolaeva OA, Ph.D. Thesis, Kyiv, Ukraine, 2011(in Ukrainian).

[9]. Anderson JC, Reese CB. Photo-Induced Fries Rearrangements. Proc. Chem. Soc. 1960; June, 217.

[10]. Frechet JMJ, Tessier TG. Poly[p(formyloxystyrene]: Synthesis and Radiation-Induced Decarbonylation. Macromolecules. 1985; 18(3): 317-20.

[11]. Li S-KL, Guillet JE. Studies of the photo-Fries reaction in solid poly(phenyl acrylate). Macromolecules. 1977; 10(4): 840-44.

[12]. Merle-Aubry L, Holden DA, Merle Y, Guillet JE. Photophysics and Photochemistry of Naphthyl Ester
Polymers in Solution. Macromolecules. 1980; 13: 113843.

[13]. Hofler T, Grieber T, Gstrein X, Trimmel G, Jakopic G, Kern W. UV Reactive Polymers for Refractive Index Modulation Based on the Photo-Fries Rearrangement. Polymer. 2007; 48: 1930-39.

[14]. Griesser T, Hofler T, Temmel S, Kern W, Trimmel G. Photolithographic Patterning of Polymer Surfaces Using the Photo-Fries Rearrangement: Selective Postexposure Reactions. Chem. Mater. 2007; 19(12): 3011-17.

[15]. Daschiel U, Höfler T, Jakopic G, Schmidt V, Kern W. Selected Polymers that Contain Aromatic Ester Units: Synthesis, Photoreactions, and Refractive Index Modulation. Macromolecular Chemistry and Physics. 2007; 208 (11): 1190-201.

[16]. Vretik LO, Syromyatnikov VG, Zagniy VV. Problem of photoalignment in the LCD's development: Synthetic routes in its solving. Mol. Cryst. Liq. Cryst, 2008; 486: 57-65.

[17]. Gunzler H, Gremlich H-U. IR Spectroscopy. An introduction. Weinheim: Wiley-VCH Verlag Gmbh \& Co.; 2002, pp.60-2.

[18]. Parfitt GD, Rochester CH. Adsorption from solution at the solid/liquid interface. Moscow, Russia: Mir; 1986.

[19]. Skopenko VV, Saranskiy LI. Coordination chemistry. Kyiv, Ukraine: Lybid, 2004 (in Ukrainian). 